\title{
Role of Psychological and Educational Guidance Center in Reducing the University Violence from Educational Science College's Students' Perspective in Counseling and Mental Health Department at World Islamic Sciences and Education University
}

\author{
Saleh Hassan Al-Daheri ${ }^{1}$ \\ ${ }^{1}$ Educational Science College, World Islamic Sciences and Education University, Amman, Jordan \\ Correspondence: Saleh Hassan Al-Daheri, Educational Science College, World Islamic Sciences and Education \\ University, Amman, Jordan.
}

Received: July 8, 2019

Accepted: August 23, 2019

Online Published: October 25, 2019

doi:10.5539/ies.v12n11p59

URL: https://doi.org/10.5539/ies.v12n11p59

\begin{abstract}
The study aimed to identify the roles of Psychological and Educational Guidance Center in Reducing the phenomenon of the university violence from the perspective of the Educational Science College's students in Counseling and Mental Health Department at World Islamic Sciences and Education University. And to achieve the study's goal, a sample consisted of 10 students of the Educational Science College was selected. A questionnaire was developed to collect data. Results showed that the level of students' degree in practicing violence was moderate and media is one of the major causes of violence at university. The researcher came up with some recommendations.
\end{abstract}

Keywords: university violence, educational college, WISE University, guidance center

\section{Introduction}

The university has considered the educational and social institution that comes after the family in its importance in terms of developing the individual's talents, capabilities and providing them with knowledge. The university aims to create the good citizen who is capable to improve and develop the society. As the university welcomes yearly students from different background and cultures, it is expected to have great differences in the interaction process among the students which cause problems and difficulties. Accordingly, it is possible to have students who are unable to interact, communicate properly with others and so many misbehaviors may show up on the surface and impede the achievement of the educational process's goals (Daheri, 2018). University violence which is not a new phenomenon showed a serious problem in the parents' ways in bringing up their children. The children started to behave aggressively towards others or properties, they are actually try to meet their needs which their families fail to do, in addition to other economic, social and psychological factors. In less civilized and developed societies, students are exposed to a set of violent behaviors starting from the domestic violence and expand to include the university violence which it's horrible effect has attracted the attention of different parties and authorities in the society (Al-Sarairah, 2009, p. 23). And so the significant role of the educational and psychological counseling center in reducing this phenomenon has aroused. The center can help the students to adapt socially to their environments and discover their talents, in addition to enhance them psychologically to have positive and effective roles in their society.

\subsection{The Problem of the Study and Its Questions}

The study aimed to identify the roles of the educational psychological counseling center in reducing the violence phenomena from the perspective of the students' of the Educational Sciences College at the World Islamic Science \& Education University. Having a look at the educational institutions, one can see that some of them suffer from problems as the spread of violence and therefore, the researcher felt interested in investigating the causes of violence and finding problems to it as well. Studies that addressed this issue were few and so the study aimed to answer the following major question and its sub-questions:

What should be done to reduce the university violence from the perspective of the educational counseling college at the World Islamic Science \& Education University? 
a) What are the most important manifestations of violence of the Educational Sciences College's students?

b) b- What are the reasons of the Educational Sciences College's students' violence from their perspective?

c) c- What are the roles of the psychological and counseling center in reducing university violence from the students' perspective?

\subsection{Significance of the Study}

1) Shedding light on the effect of violence in the socialization on the education institutions in general and the universities in particular.

2) Activating the role of Psychological and Educational Guidance Center in identifying the social problems in the educational institutions as universities.

3) Finding appropriate solutions in reducing the phenomena of university violence and proposing psychological and educational alternatives that help in reducing the violence.

\subsection{Objectives of the Study}

The study aimed to identify the role of Psychological and Educational Guidance Center in reducing the phenomenon of the university violence from the perspective of the Educational Science College's students in Counseling and Mental Health Department at World Islamic Sciences and Education University through achieving the following:

1) To reveal the roles of Psychological and Educational Guidance Center in reducing the phenomenon of the university violence in the educational institutions.

2) To propose beneficial solutions in reducing the university violence in the educational institutions as the universities.

\subsection{Terms of the study}

Linguistically, Al-Khaleel (1995) defines university violence as: "a behavior used to harm verbally or physically. According to Dbabna (2011) university violence is any offensive behavior towards students causing pain or to public,or private properties inside and outside the university. And this violence could be individually or socially.

The educational psychological counselor is the person who is specialized in the methods of individual, group, rational and religious guidance towards students, who is prepared psychologically and psychologically in the Faculty of Arts and Education, Department of Counseling and Mental Health (Dahiri, 2010).

Center of educational and psychological counseling is the center which is responsible for activities concerning educational and psychological counseling in the department of counseling and psychological health. This center has many roles as organizing workshops that aim to reduce the university violence in the college and university.

\subsection{Limitations of the Study}

- Spatial limits: the study applied on the educational Sciences College's students in Counseling and Mental Health Department at World Islamic Sciences and Education University

- Time limits: the study was carried in the second semester in the academic year 2016/2017.

\subsection{Theoretical Frame}

Violence is the hidden energy inside the human being that explodes as a reaction to external stimuli as the violence ones. And this energy converted to a behavior as vandalism and beatings among the students themselves or between students and the faculty members (Daheri, 2018). And this violence which takes place in the academic institutions has known as university violence. This type of violence becomes as source of threat to the society, and its security and stability. For its horrible and rapid widespread all around the world and for its negative effect on the people's behavior in the society, great number of authorities started to be interested in this strange phenomenon (Daheri, 2018). Violence forms can be classified into the following:

1) Physical represented by deliberate use of physical power towards others so as to hurt them.

2) Physiological represented by actions done by a person or many aim to hurt others psychologically.

3) Verbal represented by using words or expressions that do not match with others' ethics.

4) Bullying among the schools' students.

There are many reasons of university violence as reasons concerning the university, its administration, and regulations as the great increase in the students enrolled in the universities, absence of university activities that 
motivate students and enhance their creativity and talent, the university security guards' lack of efficiency and skill in dealing with students' problems, students' lack of self-esteem for social and financial situations they passed by so they started looking for ways to attract others attention and violence could be one of these ways.

- Media and its effect: when media programs highlighted violence as heroic action, students will imitate. Media needs to activate its role in spreading awareness of the importance of volunteering.

- Unemployment among the youth.

- Misunderstanding of the true religion so the possibility to have extremist groups increases.

- Lack of dialogue channels between young people and the concerned parties to solve the youth problems and the weak skills of religious and cultural persuasion by the specialized or the media.

- Political reasons: politics' priority is to achieve its own interest or goal regardless taking into account others' goals.

Al-refai (2013) added further reasons for violence at universities. First: social reasons as lack of faith, poor social legislations, media influence. And spread of exotic values. Second: economic reasons as poverty. Third: psychological reasons as failure to have healthy and social relations, deprivation of compassion and sympathy, and the individuals' high echo. Fourth: the company (friends) the most important cause of violence. Fifth: reasons related to the university and its administration as the university's regulations, the high increase in the students number in the universities, lack of curricula that motivate students' critical and creative thinking, the students' feeling of inequality, in addition to absence of justice. Violence has two major manifestations which are the students' simple violence which is a movement of rebellion while the other is the fermented Violence which the political parties and organization do to get benefit of societies' depression and desperate. The most common causes of university violence are the following (Gbari, 2013; Dbabna, 2011; Rifai, 2010): Social and economic reasons which includes: tribal fanaticism, lack of good and strong relations among the family's member and the parents' lack of the interest concerning their children behavior, unemployment, the false parental upbringing style, complicated situations that the students cannot solve, incapability to have ways to convince the students to get what they want, depression, sense of inferiority and failure, influence of media, false students' adaptation of college life, and the rapid social and economic transformations that create specific social ranks .and add new values for the youth.

- Political reasons which include the students' political Affiliation, the students' conflict on students' councils' elections and the interference of the political and intellectual parties from outside the university.

- Academic reasons: weak academic achievement is one of the reasons that make students feel depressed and become more capable to act negatively. Studies showed that great number of the participants in university violence were low achiever students.

Emotional reasons: the most common reason for university violence is the relationship between a male and female. In other words, the female is mainly the reason behind the violence and this may due to the students' lack of awareness and false brining up

\subsection{Previous Studies}

Al-Shahri (2003) conducted a study aimed to identify violence at secondary schools from the teachers' and teachers' perspective. The sample of the study consisted of 3610 students and 55 teachers. A questionnaire was designed to achieve the study's goals. Results showed lack of differences between the teachers' and students' views towards school violence. Al-Bashri's (2004) study aimed at identifying the role of the educational counselor in decreasing the school violence from the counselors' perspective in Aseer Region in Saudi Arabia. The sample of the study which consisted of 160 educational counselors was selected from public and private secondary schools. The Descriptive Approach was adopted. Results revealed the fear and anxiety from the future may make people feel hopeless and be aggressive towards others. In their qualitative study, Al-Zuid and Al-Habashna (2006) tried to identify the reasons of school violence in the Jordanian public schools. The researchers interviewed 16 cases of school violence chosen from the school records in the education directorates in 6 governorates. Results showed that some teachers' misbehavior towards students, students' weak achievement and carelessness and the false companies' effects, in addition to the students' abnormal psychological and personal characteristics. In USA, Crump conducted a study aimed to identify the tendencies of secondary schools about the use of violence. The sample of the study which consisted of 800 houses was interviewed orally. Results showed the family's social and economic levels have great role in forming attitudes towards violence. The students with moderate economic and social levels were less oriented to use violence than those who are poor. 
Duckworth-Loche (2000) conducted a study aimed at identifying the views of administrators, counselors, teachers and students concerning school safety and violence in selected secondary schools" in Louisiana University in USA. 58 members were chosen as a sample of the study. The descriptive and analytic Approach was adopted. Results revealed that schools' managers believe that their schools were less secure while teachers and the counselors believe the opposite.

\section{Methodology}

The researcher adopted the analytic and descriptive approach in collecting data and then the researcher interpret the data after analyzing it statistically.

\subsection{Population of the Study}

The population of the study consisted of all the students in Educational Sciences College in the psychological and counseling department in the second semester for the academic year2018/2019.

\subsection{Sample of the Study}

The sample of the study consisted of 10 students represented the students in Educational sciences College in the psychological and counseling department in the second semester for the academic year2018/2019.

\subsection{Tool of the Study}

To achieve the study's goals, a questionnaire consisted of 28 items was developed. It covers the following fields:

First: violence aspects among the students

Second: reasons of students' violence

Third: the roles of the educational psychological and counseling center in the college.

The questionnaire was presented to a group of arbitrators who are members in the academic staff in the WISE University to check the tool items' validity. Their notes were taken into account and some changes were done and so the tool's apparent validity was checked. To check the reliability of the tool, Chronbach Alpha was used as it is illustrated in Table 1. Results showed that all values of Chronbach Alpha for all the variables were higher the $(0.60)$ which is considered acceptable in the human studies.

Table 1. Results of Cronbach Alpha

\begin{tabular}{lc}
\hline Variables of the study & Reliability Coefficient \\
\hline violence aspects among the students & 0.75 \\
reasons of students' violence & 0.83 \\
roles of the educational psychological and counseling center in the college & 0.96 \\
Total degree & 0.94 \\
\hline
\end{tabular}

\subsection{Procedures of the Study}

- Reviewing the related and previous literature of the subject of the study which is violence at universities.

- Developing the tool of the study.

- Checking the study's tool's reliability and validity.

- Distributing the questionnaires into the sample of the study.

- Collecting data and analyzing it statistically using the means, standard deviations, and one-Sample test.

\section{Results}

First: results concerning the first question: What are the violence aspects among the students of the Educational Sciences College in WISE University from their perspective? To answer this question, means and standard deviations were used as it is illustrated in Table 2. 
Table 2. Means and Standard Deviations of the sample' respondents concerning the aspects of violence

\begin{tabular}{llcccc}
\hline $\mathrm{N}$ & Item & $\mathrm{M}$ & $\mathrm{STd}$ & Rank & Value \\
\hline 4 & Writing immoral expressions on the university's walls & 3.70 & 1.64 & 1 & High \\
9 & Threatening the female students & 3.40 & 1.78 & 2 & Moderate \\
8 & Assaulting on the students verbally & 3.20 & 1.81 & 3 & Moderate \\
6 & Spreading rumors in the college & 2.20 & 1.75 & 4 & Low \\
7 & Saying impolite words to others & 2.00 & 1.49 & 5 & Low \\
5 & Rebellion against the College Deanship & 1.90 & 1.45 & 6 & Low \\
1 & Assaulting on the academic staff & 1.20 & 0.63 & 8 & Low \\
3 & Destroying the university's proprieties & 1.00 & 0.00 & 9 & Low \\
& Total M & 2.90 & 0.90 & & Moderate \\
\hline
\end{tabular}

The previous table showed that the means of the level of the violence aspects among the students in the department ranged from 1.00 to 3.70 . Also, the table showed that item 4 got the highest level with a mean (3.70) while item 2 came last with a mean (1.00)

Second: results concerning the second question: What are the reasons of the Educational Sciences College's students' violence from their perspective?

To answer this question, means and standard deviations were used as it is illustrated in Table 3.

Table 3. Means and Standard Deviations of the sample' respondents concerning the reasons of the students' violence

\begin{tabular}{llcccc}
\hline $\mathrm{N}$ & Item & $\mathrm{M}$ & $\mathrm{Std}$ & Rank & Value \\
\hline 9 & Effect of media(movies violence) & 3.80 & 0.75 & 1 & High \\
1 & Lack of faith & 3.20 & 1.40 & 2 & Moderate \\
6 & Fear and anxiety of the future & 3.20 & 1.55 & 3 & Moderate \\
8 & Bad company & 3.10 & 1.73 & 4 & Low \\
7 & Low economic income & 3.00 & 1.83 & 5 & Low \\
10 & Absence of one of the parents or both from home & 2.90 & 1.45 & 6 & Moderate \\
4 & Low feeling of psychological stability & 2.40 & 1.58 & 7 & Moderate \\
5 & Lack of self esteem & 2.20 & 1.40 & 8 & Low \\
2 & media underestimation of the religious values & 2.10 & 1.10 & 9 & Low \\
3 & Poor guidance in the religious education & 1.50 & 0.85 & 10 & Low \\
& Total & 3.04 & 1.01 & & Moderate \\
\hline
\end{tabular}

The previous table showed that the means of the level of the reasons of violence among the students in the department ranged from 1.50 to 3.80 . Also, the table showed that item 9 got the highest level with a mean (3.80) while item 3 came last with a mean (1.50)

Third: results of the second question: What are the roles of the psychological and counseling center in reducing university violence from the students' perspective?

To answer this question, means and standard deviations were used as it is illustrated in Table 4. 
Table 4. Means and Standard Deviations of the sample' respondents concerning the roles of the psychological and counseling center in reducing university violence from the students' perspective

\begin{tabular}{llcccc}
\hline $\mathrm{N}$ & Item & $\mathrm{M}$ & Std & Rank & Level \\
\hline 1 & Strengthening the religious and moral values & 4.80 & 0.42 & 1 & High \\
2 & Enhancing loyalty & 4.60 & 0.70 & 2 & High \\
6 & Honorary board for the good behavior & 4.50 & 1.08 & 3 & High \\
5 & A ware students of the unaccepted behavior & 4.20 & 1.23 & 4 & High \\
3 & Aware students of age growth stages & 4.10 & 1.10 & 5 & High \\
9 & Keeping in touch with the parent & 3.80 & 1.55 & 6 & High \\
4 & Identifying students' health and psychological conditions & 3.60 & 1.35 & 7 & Moderate \\
8 & Creating a committee to deal with the abnormal behavior and modify it. & 3.60 & 1.51 & 8 & Moderate \\
7 & Engage students in the psychological and educational counseling programs and activities. & 3.50 & 1.51 & 9 & Moderate \\
& Total & 4.08 & 0.67 & & High \\
\hline
\end{tabular}

The previous table showed that the means of the level of the roles of the psychological and counseling center in reducing university violence from the students' perspective ranged from 3.50 to 4.80 . Also, the table showed that item 1 got the highest level with a mean (4.80) while item 7 came last with a mean (3.50). and to identify the effect of the roles of the educational psychological counseling center in reducing the university violence, $\mathrm{T}$ test was used as it is shown in Table 5.

Table 5. Results of one sample t-test

Sig at $(0.05)=(300)$.

\begin{tabular}{cccccc}
\hline M & Std & Tabulated (T) & Calculated (T) & Fd & Sig. \\
\hline 4.08 & 0.67 & 1.96 & 9.096 & 9 & $* 0.000$ \\
\hline
\end{tabular}

It is noted from the Table 5, that there was an effect to the roles of the educational psychological counseling center in reducing the university violence with a mean (4.08). Results also showed statistical differences at (0.05) between the respondent' responses and default scale with calculated T (9.09) which is higher than the tabulated T and so there is an effect to the roles of the educational psychological counseling center in reducing the university violence from the students' perspective.

\section{Discussion and Recommendations}

Results concerning the first question: "What are the violence aspects among the students of the Educational Sciences College in WISE University from their perspective?" showed that the level of students' degree in practicing violence was moderate with a mean (2.90) and this may due to students' lack of faith and blind imitation to their false friends and this results in agreement with the Al-Bashri's (2004) study that showed the sixth graders' degree of practicing violence was moderate. Discussion of the results of the second question: what are the causes of the university violence of the educational college students at the counseling and psychological health department from their perspective?

Results concerning the second question showed that the effect of media especially the violence movies was the most significant reason of university violence from the students' perspective with a mean (3.04) and this result may due to learning strange and exotic behaviors to the society that encourage violence by watching movies . In other words, this result showed the negative effect of media on the students who imitate what they watch a way from their parents' control. This result agrees with the study's results of Duckworth-Loche (2000) which revealed that one of the important causes of violence was the media effect.

Results concerning the third question: "What are the Educational and psychological counseling center's most significant roles in reducing the educational Science College students' university violence?" showed that the religious values was the most significant role which the center plays in the university with a mean (3.04) and this may due to the importance of religious awareness in reducing the negative practices especially violence against students and others' properties and highlighting the effect and role of affiliation to the place where one lives which helps in stop practicing violence. This result is in agreement with the study of Al-Bashri (2000) which showed the degree of the sixth female graders' practice of violence was high.

Proposed solutions for university violence: 
- Engage the students in activities that meet their needs, focusing on their weakness points to be treated, hopefully.

- Enhancing the role of the security guards in the university and rehabilitating them continuously.

- Ensuring the necessity of obeying the university's laws and regulations to avoid punishment.

- Developing and encouraging the cooperation among the university students.

- Raising students' awareness of the concept of violence, its causes and effect by leaflet distribution.

- Punishing the students who take part in violence by the university administration.

- Organizing workshops that help in habilitating the students and developing their mental and cognitive abilities.

- Activating the positive dialogue strategy among the students.

- Granting the students a certificate of good behavior during their studying in the university.

- Activating the media role in guiding the youth positively.

- Having a compulsory course in the universities that aware students of values as forgiveness, respect and love.

\section{Recommendations}

Based on the results, the researcher recommended the following:

1) Carrying more related research and focusing on one study cases.

2) Organizing workshop to enhance the awareness of the employees working in counseling field and increasing the number of the educational counselors.

3) The cooperation between the university's employees to a successful and efficient academic process.

4) Increasing the academic departments' heads' contribution in organizing meetings addressing the issue of violence; its causes, effects and solutions.

\section{References}

Al-Bashri, A. (2000). Violence: Causes and effect. Dar Safa for publishing and distribution, Cairo, Egypt.

Al-Bashri, A. (2004). Role of students director in restricting school violence from the perspective of students' directors in Asir Educational Region (Unpublished thesis). Naif Arab University for Security Sciences, Saudi Arabia.

Al-Khaleel, A. (1995). University violence. Dar kotb, Ryadh, Saudia Arabia.

Al-Sarairah, K. (2009). Causes of students' violence towards teachers and administrators in the public schools in Jordan from the perspective of the students, teachers and administrators. Jordanian Journal in the education sciences, 2.

Al-Shahri, A. (2003). Violence in the secondary schools from the teachers' and students' perspective (Unpublished Thesis). Naif Arab University for Security Sciences, Saudi Arabia.

Al-Zuid, M., \& Al-Habashna, M. (2006). School Violence in the public schools: Forms and causes. Department of research and education development, Ministry of Education, Amman, Jordan.

Daheri, S. A. (2018). Basics of health and neurological and behavioral therapy psychology. Dar Safa', Amman, Jordan.

Dahiri, S. (2010). Foundations of psychological and educational sociology and its theories. Dar Manhal, Amman, Jordan.

Dbabna, M. (2011). Education activities and its development methods. Dar Wael, Amman.

Duckworth-Loche, S. (2000). Perceptions of administrators, counselors, teachers, and students concerning school safety and violence in selected secondary schools in North Louisiana (Doctoral dissertation, Louisiana Tech University). Retrieved from https://digitalcommons.latech.edu/cgi/viewcontent.cgi?article= $1166 \&$ context $=$ dissertations

Gbari, N. (2013). Schools and students'behaviors. Joma for publishing, Tunisia.

Rifai, A. (2010). Violence at schools. Al-Bara for distribution, Oman. 


\section{Copyrights}

Copyright for this article is retained by the author(s), with first publication rights granted to the journal.

This is an open-access article distributed under the terms and conditions of the Creative Commons Attribution license (http://creativecommons.org/licenses/by/4.0/). 